$100 \mu \mathrm{mol} / 1$ (about $3 \mathrm{mg} / \mathrm{l}$ ) of soluble silicon is necessary to protect against the absorption of aluminium, that is all forms of aluminium in the diet. ${ }^{4}$ Unfortunately, we did not have historical data on silicon levels in water before the onset of dementia. We therefore applied the current silicon levels to our case-control pairs and found a non-significant OR of 0.8 based on the postulated protective level of $3 \mathrm{mg} / 1$ of dissolved silicon in water. The weight that can be placed on this result is debatable given that the proposed protective factor was measured after the disease onset, albeit based on the address before the onset of dementia. However, silicon levels in the same water source are relatively stable with time, although the source of water for a particular area may have been changed. Additionally, relatively few of the samples had a silicon concentration of $3 \mathrm{mg} / \mathrm{l}$ or above in order to test the threshold hypothesis of silicon in water.

Silicon determines the bioavailability of all dietary exposures to aluminium. It is availability rather than simple exposure which is important if aluminium is causally involved in $\mathrm{AD}$; we therefore suggest that the possible preventive role of silicon in PDAT requires further investigation. For example, the incidence rates of $\mathrm{AD}$ in areas in which the concentration of silicon is high ( $3 \mathrm{mg} / \mathrm{l}$ or above in water) could be compared with those in areas of low silicon values.

1 Forster DP, Newens AJ, Kay DWK, Edwardson JA. Risk factors in clinically diagnosed presenile dementia of the Alzheimer type: a case-control study. 1994 f Epidemiol Community Health 1995;49:253-58.

2 Birchall JD, Chappell JS. Aluminium, water chemistry, and Alzheimer's disease. Lancet 1989;i:953.

3 Edwardson JA, Moore PB, Ferrier IN, Lilley JS, Newton GWA, Barker J et al. Effect of silicon on gastrointestinal absorption of aluminium. Lancet 1993;342:211-2.

4 Birchall JD. The role of silicon in aluminium toxicity. In: Lord Walton of Detchant ed. Alzheimer's disease and the environment. London: Royal Society of Medicine, 1991. Round Table Series 26.

5 Parkinson IS, Ward MK, Kerr DNS. A method for the routine determination of aluminium in serum and water by flameless atomic absorption spectrometry. Clinica Chimica Acta 1982;125:125-33.

\title{
Asthma history and sociodemographic characteristics in elderly French people
}

\author{
Chakib Nejjari, Jean François Tessier, Pascale Barberger-Gateau, Luc Letenneur, \\ Jean François Dartigues, Roger Salamon
}

Asthma is a disabling chronic disease, especially in elderly people in whom prevention of the loss of autonomy becomes very important. ${ }^{1}$ Recent data have also suggested that mortality related to asthma has increased over the past 10 years in both Britain and France, particularly in the elderly. ${ }^{2}$ There are, however, few epidemiological data on asthma in this group.

This was a cross sectional study. Based on a cohort of subjects aged 65 and over (Paquid cohort), we aimed to investigate the prevalence and sociodemographic characteristics of self reported asthma in this population.

\section{INSERM U 330,}

Université de

Bordeaux II, 146 rue

Léo-Saignat, F 33076

Bordeaux Cedex,

France

C Nejjari

J F Tessier

P Barberger-Gateau

L Letenneur

J F Dartigues

R Salamon

Correspondence to:

Dr J F Tessier.

Accepted for publication January 1995

f Epidemiol Community Healt 1995;49:324-325
Methods: Paquid is a cohort of 3777 dwellers, representative of the population aged 65 and over in two administrative areas of south western France (Gironde and Dordogne). Baseline data were collected in 1988-89. The Paquid questionnaire included sociodemographic characteristics: age (in years), sex, main lifetime occupation (housewives, farm workers, blue collar workers, and white collar workers), smoking status (current, former, and never smokers), and many variables on health status, disability, cognitive performance, and medication. Details of the Paquid methodology have been published elsewhere. ${ }^{3}$
Data for this study were taken from the third year of the follow up. A total of 2406 subjects (63.7\% of the initial sample) were involved. Asthma identification was based on two questions: (1) "Have you ever had asthma?" and (2) "Did you have at least one asthma attack in the last 12 months?" Subjects were categorised according to their smoking history.

The prevalence of asthma was evaluated in relation to sex, smoking status, and lifetime occupation. An association between former work and asthma was determined by logistic regression analysis. The dependent variable was asthma history (coded 1 versus 0 ). Explanatory variables were age (in years), sex (women versus men), smoking history (current smokers, and former smokers versus never smokers), and former work (housewives, farm workers, and blue collar workers versus white collar workers).

Results: Of 2406 subjects, 2355 (97.5\%) responded to the questions on asthma symptoms (979 men and 1376 women). A total of 144 subjects $(6 \cdot 11 \%)$ reported asthma and 58 $(40.2 \%)$ of them at least one attack in the last 12 months. The mean (SD) age was lower in subjects with a history of asthma compared 
Relationship between asthma and principle lifetime work

\begin{tabular}{|c|c|c|c|}
\hline \multirow{2}{*}{$\begin{array}{l}\text { Professional activity } \\
\text { (versus white collar } \\
\text { workers) }\end{array}$} & \multirow{2}{*}{$\begin{array}{l}\text { Proportion }(95 \% C I) \text { of } \\
\text { subjects with asthma } \\
\text { history (\%) }\end{array}$} & \multicolumn{2}{|l|}{ Risk for asthma } \\
\hline & & $\begin{array}{l}\text { Crude OR } \\
(95 \% C I)\end{array}$ & $\begin{array}{l}\text { Adjusted OR } \\
\text { (age, sex, smoking) }\end{array}$ \\
\hline $\begin{array}{l}\text { Farm workers } \\
(n=367)\end{array}$ & $8 \cdot 72(7 \cdot 83,11 \cdot 61)$ & $2 \cdot 11(1 \cdot 26,3 \cdot 56)$ & $2.35(p<0.0007)$ \\
\hline Blue collar workers & $7 \cdot 10(5 \cdot 40,8 \cdot 74)$ & $1.68(1.09,2 \cdot 62)$ & $1.85(p<0.004)$ \\
\hline $\begin{array}{l}(n=905) \\
\text { Housewives } \\
(n=220)\end{array}$ & $4 \cdot 61(1 \cdot 82,7 \cdot 40)$ & $1.05(0.48,2 \cdot 25)$ & $1 \cdot 3$ (NS) \\
\hline $\begin{array}{l}\text { White collar workers } \\
(n=833)\end{array}$ & $4 \cdot 32(2 \cdot 94,5 \cdot 70)$ & & \\
\hline
\end{tabular}

with others: $76 \cdot 4$ (5) versus $77 \cdot 4(6)(\mathrm{p}<0.03)$. The prevalence was higher in men than in women $(7 \cdot 35 \%$ (95\% confidence interval (CI) $5 \cdot 72 \%, 8 \cdot 98 \%)$ and $5.23 \%(95 \%$ CI $4.05 \%$, $6.41 \%)$ respectively).

A history of asthma was more prevalent $(\mathrm{p}<0.001)$ in former smokers $(8.28 \%(95 \% \mathrm{CI}$ $6 \cdot 12 \%, 10.44 \%)$ ) than in current smokers $(4 \cdot 67 \%(95 \% \mathrm{CI} 1 \cdot 84 \%, 7 \cdot 50 \%))$ and never smokers $(5 \cdot 43 \%(95 \%$ CI $4 \cdot 29 \%$ to $6 \cdot 57 \%)$ ).

The table gives the proportion with a history of asthma in each occupational category. We could classify only 2325 subjects into the four categories of activity described above. The highest proportions reporting asthma were farm workers $(8 \cdot 72 \%(95 \% \mathrm{CI} 5 \cdot 8 \%, 11.61 \%))$ and blue collar workers $(7 \cdot 10 \%$ (95\%CI $5 \cdot 40 \%$, $8 \cdot 74 \%)$ ) and the lowest white collar workers $(4 \cdot 32 \%(95 \%$ CI $2 \cdot 94 \%, 5 \cdot 70 \%)$ ).

Compared with white collar occupations, farm workers (odds ratio [OR] $2.35(95 \% \mathrm{CI}$ $1.42,3.89$ )) and blue collar workers (OR 1.85 (95\% CI $1 \cdot 21,2 \cdot 83)$ ) were more likely to report asthma after controlling for age, sex, and smoking history.

Discussion: These results show that asthma is not uncommon in the elderly in France. It is difficult to give a simple definition of asthma in the elderly in either clinical practice or epidemiological studies. Asthma is often associated with chronic bronchitis $-29 \cdot 86 \%$ of asthmatics in our sample had a history of this. Of the asthmatics, $6.94 \%$ were current smokers and $36 \cdot 11 \%$ former smokers. This fact is more important, particularly in asthmatic men in whom $43.06 \%$ have a chronic bronchitis (versus $16.70 \%$ in women) and $72.22 \%$ are current or former smokers (versus $13.89 \%$ in women).
Because of this we have adjusted for smoking history in our logistic regression analysis.

To evaluate asthma prevalence and sociodemographic characteristics of the sample, we focused on the cumulative asthma history. The reason for this was the small number of subjects reporting asthma attacks in the previous 12 months. All our subjects were retired, and our results stress the risk of asthma linked to occupation, even after retirement. Despite some bias such as survivor effect and impaired memory, asthma was more prevalent in farm and blue collar workers, even after controlling for age, sex, and smoking history.

Although the relative risk of asthma in retired farm workers is high, our findings rely on the respondent's own assessment. In farmers, there is an increased risk of extrinsic allergic alveolitis (EAA) and other occupational lung diseases, and we cannot exclude the possibility that some of the reported asthma may in fact have been EAA, which could only be assessed by respiratory function test and chest $x$ ray. There might also be diagnostic confusion between occupational groups which could account for some of the excess risk, particularly in farm workers. In the Paquid cohort, we had already found that farmers had a higher risk of dyspnoea than white collar occupations. ${ }^{3}$ The respiratory risk in farming has been found in other studies, but most of these were in working people and concerned chronic, non-specific lung diseases in particular. ${ }^{4}$ In our study, blue collar workers were also more at risk for asthma. Conditions of work and exposure to pollutants could explain this, as has been shown in many studies of younger subjects at work. ${ }^{5}$ These data indicate that it will be useful to analyse the long term and specific effect of each exposure on asthma and bronchial hyperresponsiveness in elderly.

1 Nejiari C, Tessier JF, Barberger-Gateau P, Jacamin H, Dartigues JF, Salamon R. Functional status of elderly people treated for asthma-related symptoms: a population-based treated for asthma-related symptoms: a population
case-control study. Eur Resp f 1994;7:1077-83.

2 Cooreman J, Segala C, Henry C, Neukirch F. Trends in asthma-induced mortality in France from 1970-90. Tubercle Lung Disease 1994;75:182-7.

3 Nejjari C, Tessier JF, Dartigues JF, Barberger-Gateau P, Letenneur L, Salamon R. The relationship between dyspnoea and main lifetime occupation in elderly community dwellers. Int $\mathcal{F}$ Epidemiol 1993;5:848-54

4 Terho EO, Husman K, Kauppinen T. Proceedings of the international symposium on work-related respiratory disorders among farmers. Eur $\mathcal{f}$ Resp Dis 1987; Suppl 154

5 Heederik D, Pouwels H, Kromhout H, Kromhout D. Chronic Non-Specific Lung Diseases and occupational exposure estimated by means of a job exposure matrix: the Zutphen study. Int $\mathcal{F}$ Epidemiol 1989;18:382-89. 